\title{
US perspective
}

\author{
Hebert Alberto Vargas \\ From International Cancer Imaging Society Meeting and 15th Annual Teaching Course (ICIS 2015) \\ London, UK. 5-7 October 2015
}

There are many key elements necessary to maximize the clinical utility of diagnostic imaging exams, including a pertinent clinical indication, adequate technical acquisition, accurate interpretation and effective communication of the imaging findings. The literature suggests that structured reporting in radiology leads to clearer and more thorough communication of relevant diagnostic findings than does conventional, free-form reporting. In a study of body oncologic CT examinations, structured reports were given significantly higher satisfaction ratings by both radiologists and referring physicians compared to "free-form" reports [1]. Barbosa et al. found that in addition to being preferred by the majority of the radiologists and endocrinologists participating in a study evaluating thyroid ultrasounds, the use of structured reporting resulted in improved standardization of thyroid finding descriptors [2]. A study of coronary CT angiograms found an improved inter-observer agreement for the number of vessels with significant stenosis when a structured reporting software which required the radiologist to explicitly state which vessels were involved was used [3]. Other structured reporting software with features such as drop-down menus which facilitate data entry and minimize the amount of freetext entries have been shown to aid not only data comprehension but also reduce the length of time required for aortic aneurysm imaging [4].

However, the benefits of structured reporting cannot be accepted dogmatically. An accurate interpretation reported in "free-form" style is more clinically useful than a structured report containing erroneous information. Furthermore, the terminology used in structured reports also requires standardization. Khorasani et al reported poor agreement between radiologists and nonradiologists in the interpretation of the most commonly used phrases in radiology reports [5]. In recent surveys gathering opinions about radiology reports, $20 \%$ of the

\footnotetext{
Department of Radiology, Memorial Sloan Kettering Cancer Center, 1275
} York Avenue, New York, NY 10065, USA

C 2015 Vargas This is an Open Access article distributed under the terms of the Creative Commons Attribution License (http:/ creativecommons.org/licenses/by/4.0), which permits unrestricted use, distribution, and reproduction in any medium, provided the original work is properly cited. The Creative Commons Public Domain Dedication waiver (http://creativecommons.org/publicdomain/ responding clinicians indicated that they found the language and style of radiology reports unclear [6]. Another study found that referring clinicians may reach different conclusions when reading the same reports [7].

Another important issue relevant to standardized reporting is the expression of diagnostic certainty. Radiologists are often tasked with summarizing multiple findings and rendering an opinion with regards to potential explanations for the radiographic findings. There are scenarios in which no differential diagnoses are warranted and the findings are reported in terms of the absolute presence or absence of a pathologic process (e.g. "no fracture"). In other cases the findings are not definitive, and radiologists need to indicate their level of certainty for their interpretation of the imaging findings. In a study of patients with prostate cancer, 38 different terms were used in MRI reports to express the levels of certainty for the presence of extracapsular extension, prior to the introduction of a 5-point "certainty lexicon" [8]. The lexicon not only simplified the communication of the radiologists' level of suspicion but also allowed more objective quantification of the diagnostic performance of MRI for diagnosing ECE, with a reported area under the curve of 0.85 [8]. The development of standardized "lexicons" to indicate the radiologists' level of certainty for interpreting the imaging findings should therefore be considered an integral component of structured reports.

\section{Published: 2 October 2015}

\section{References}

1. Schwartz LH, Panicek DM, Berk AR, Li Y, Hricak H: Improving communication of diagnostic radiology findings through structured reporting. Radiology 2011, 260:174-181.

2. Barbosa F, Maciel LM, Vieira EM, Azevedo Marques PM, Elias J, Muglia VF: Radiological reports: a comparison between the transmission efficiency of information in free text and in structured reports. Clinics 2010, 65:15-21.

3. Ghoshhajra BB, Lee AM, Ferencik $M$, et al: Interpreting the interpretations: the use of structured reporting improves referring clinicians' zero/1.0/) applies to the data made available in this article, unless otherwise stated.

() Biomed Central 
comprehension of coronary $\mathrm{CT}$ angiography reports. Journal of the American College of Radiology: JACR 2013, 10:432-438.

4. Karim S, Fegeler C, Boeckler D, HS L, Kauczor HU, von Tengg-Kobligk H: Development, implementation, and evaluation of a structured reporting web tool for abdominal aortic aneurysms. JMIR research protocols 2013, 2:e30.

5. Khorasani R, Bates DW, Teeger S, Rothschild JM, Adams DF, Seltzer SE: Is terminology used effectively to convey diagnostic certainty in radiology reports? Academic radiology 2003, 10:685-688.

6. Bosmans JM, Weyler JJ, De Schepper AM, Parizel PM: The radiology report as seen by radiologists and referring clinicians: results of the COVER and ROVER surveys. Radiology 2011, 259:184-195.

7. Bastuji-Garin S, Schaeffer A, Wolkenstein P, et al: Pulmonary embolism; lung scanning interpretation: about words. Chest 1998, 114:1551-1555.

8. Wibmer A, Vargas HA, Sosa R, Zheng J, Moskowitz C, Hricak H: Value of a Standardized Lexicon for Reporting Levels of Diagnostic Certainty in Prostate MRI. AJR Am J Roentgenol 2014, 203(6):W651-W657.

doi:10.1186/1470-7330-15-S1-O3

Cite this article as: Vargas: US perspective. Cancer Imaging 2015

15(Suppl 1):O3.

\section{Submit your next manuscript to BioMed Central} and take full advantage of:

- Convenient online submission

- Thorough peer review

- No space constraints or color figure charges

- Immediate publication on acceptance

- Inclusion in PubMed, CAS, Scopus and Google Scholar

- Research which is freely available for redistribution

Submit your manuscript at www.biomedcentral.com/submit 